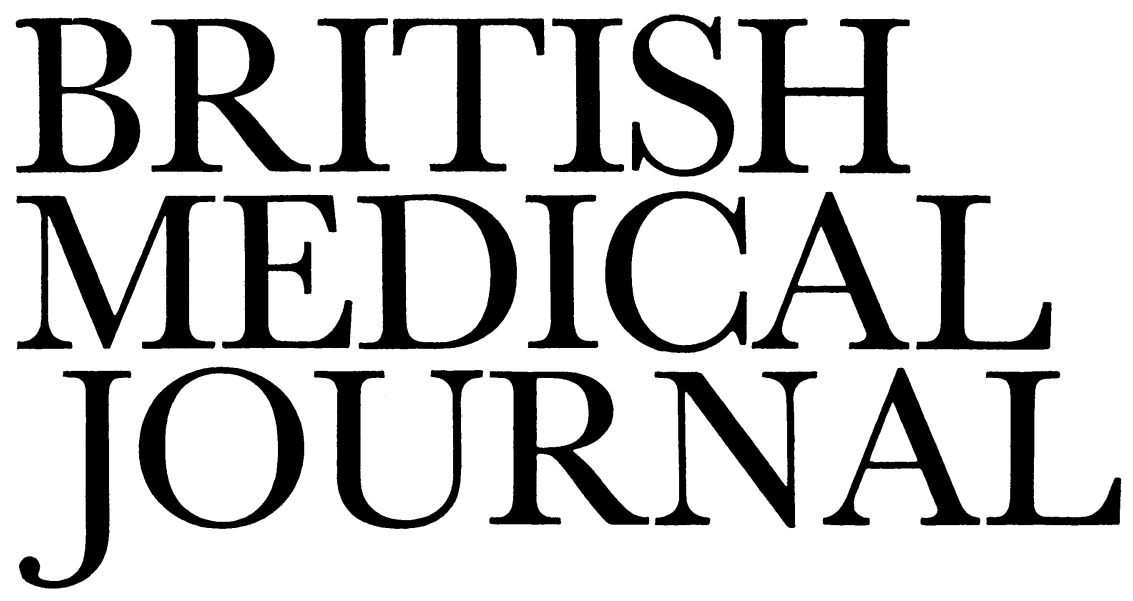

LONDON, SATURDAY 14 MAY 1983

\title{
Familial susceptibility to cancer
}

A common cause of anxiety among patients with cancer and their relatives is that cancer may run in families. Patients worry about their children, and relatives feel themselves to be more at risk because it is "in the family." Some families do have more cases of cancer than others, but there are many reasons for this and not all of them necessarily mean that hitherto unaffected family members have an unusually high risk of developing the disease. For example, several family members, all or most of them elderly, may have a variety of different cancers. In such families it is perfectly reasonable to assume that the important factor is age and to advise relatives that their risk of cancer is no higher than that of any other family. Common exposure to an environmental hazard may lead to several cases of cancer, usually of the same type, in a single family, especially in small communities dependent on a single industry. Obviously, only exposed members are at risk, but, as in the case of exposure to asbestos, family members not employed in the high risk occupation may have to be included among the exposed population. ${ }^{1}$ Where the environmental exposure is massive (as with asbestos exposure and smoking) any genetic contribution is likely to be small.

In some families there is a clearly inherited susceptibility to cancer, usually of one type. Some of these families are well aware of the familial nature of the disease and of the need for early and regular examination. Though such families may be rare in the experience of a single clinician, they may present a substantial problem on a national scale. For example, Lips et al suggest that there may be as many as 500 cases of multiple endocrine neoplasia type 2 (Sipple's syndrome) in the Netherlands requiring the screening of large numbers of family members for medullary carcinoma of the thyroid. ${ }^{2}$ Even with dominantly inherited susceptibility to cancer, however, the families may be quite unaware of the familial risk and it is then the doctor's task to ensure that the necessary investigations are carried out at the appropriate time, especially when, as . in Sipple's syndrome, a specific screening test is available and the prognosis is better for cases diagnosed early. Similarly, when a patient is found to have multiple colonic polyps, family members (who will not be aware of the risk) should be examined, since virtually all the carriers of the dominant polyposis gene are likely to develop cancer and the results of early surgery are good. Much can be done by the well informed doctor, but unless a mechanism exists for recording the familial nature of these and similar diseases and defining who is at risk it is all too easy for such families to be without advice when confronted by a problem that may be extremely alarming. One simple step would be to adopt a system whereby the hospital clinician sends the family doctor a standard card drawing attention to the familial nature of the disease as a reminder and a permanent record in the patient's case notes. There is also a strong case for establishing central or regional registers of families with dominant cancer susceptibility against which individual cases can be checked.

For recessively inherited susceptibility to cancer the problem is different, since the patient's primary complaint is often apparently unconnected to any susceptibility to cancer. The patient, the parents, and often the doctor are all unaware of the risk of cancer. For example, in a patient with a cerebellar ataxia presenting with a radiological shadow in the lung will the average doctor know that patients with ataxia-telangiectasia have a high risk of lymphoma ${ }^{3}$ and also are radiosensitive ? ${ }^{4}$ In such families, where two subjects may be affected, the parents usually have more immediate concerns than worrying about an increased risk of cancer in the medium term. How much, then, should doctors burden them with this worry? If the answer is little or not at all, it places a very special responsibility on the doctor to be aware of such risks.

Though important in total, all of these risks are rare, and the most pressing problems of cancer susceptibility therefore rest with the common cancers, where the familial risks are not well defined but the fears of the families are real. Almost $60 \%$ of all cancer mortality in Britain is attributed to four sites: the lung, breast, stomach, and colon and rectum together. ${ }^{5}$ Although environmental causes are very important, retrospective genetic studies comparing the morbidity or mortality among first degree relatives of patients with these cancers either with a control group of relatives or with the expected population rates show a significant twofold to fourfold excess of cancers of the same type. ${ }^{6}$ If such an increase were distributed evenly over all families and all first degree relatives it would not be a matter for serious concern for the individual. Increasing evidence, however, suggests that much of the risk may be concentrated in a relatively few families with a very high risk. ${ }^{7}$ Thus each family must be 
offered advice only on the basis of the unique features of the family history.

To put the problem into practical terms, a patient with cancer of the breast whose mother or sister also has this disease wants to know if her daughters are at risk. The lifetime risk of a woman developing breast cancer in Britain is about one in $17 .{ }^{8}$ The probability of one first degree relative of any woman developing breast cancer by chance is therefore quite high (about one in six, given that there are three first degree relatives). Thus it would be reasonable to reassure a postmenopausal woman with unilateral cancer of the breast with one other close relative affected at about the same age that there is little if any excess risk for other members of the family. On the other hand, if both breast cancers occur in young women, especially if there is evidence of pre-existing benign breast disease ${ }^{8}$ or if one of the cases is bilateral, ${ }^{9}$ then the risk to other family members may be considerable.

Families where there is a clear excess of other common cancers ${ }^{10}$ may be characterised by the occurrence of the same type of cancer-for example, cancer of the colon-but some families have an excess of adenocarcinomas of different tissues ${ }^{11}$ or even cancers of diverse types. ${ }^{19}$ An unusual familial risk would be indicated either by several cases of the same type or by exceptionally early ages at onset or both. By bearing in mind the incidence of the common cancers the doctor will be able to reassure most families after taking a careful family history, but it is equally important for him to ensure that the rare high risk families are screened appropriately.

Carcinoma of the bronchus raises a totally different problem. Though there is some evidence of a genetic component, the environmental cause is clear and overwhelming. Even if there were evidence that smokers who develop lung cancer were genetically susceptible, the only reasonable advice to give to patients anxious about lung cancer in the family is to avoid smoking of any kind.

\section{G HARNDEN}

Professor of Cancer Studies,

University of Birmingham,

Birmingham B15 2T

' Newhouse ML, Thompson H. Mesothelioma of pleura and peritoneum following exposure to asbestos in the London area. $\mathrm{Br} \mathcal{f}$ Ind $\mathrm{Med}$ $1965 ; 22: 261-9$

2 Lips KJM, Van der Sluys Veer JAAP, Struyvenberg A, Geerdinka RA. Genetic predisposition to cancer in man. Advantages and problems of central registration and screening of families at risk. $\mathrm{Am} \mathcal{F}$ Med 1982; 73:305-7.

${ }^{3}$ Spector BD, Filipovitch AH, Perry GS, Kersey JH. Epidemiology of cancer in ataxia-telangiectasia. In: Bridges BA, Harnden DG, eds. Ataxia-telangiectasia-a cellular and molecular link between cancer, neuropathology and immune deficiency. Chichester: Wiley, 1982:103-38.

4 Taylor AMR, Harnden DG, Arlett CF, et al. Ataxia telangiectasia: a human mutation with abnormal radiation sensitivity. Nature 1975; $258: 427-9$.

${ }^{5}$ Alderson $M$. The extent of the cancer problem. In: Alderson $M$, ed. The prevention of cancer. London: Edward Arnold, 1982:3-19.

${ }^{6}$ Anderson DE. Familial susceptibility. In: Fraumeni JF, ed. Persons at high risk of cancer. New York: Academic Press, 1975:39-54.

' Lynch HT, ed. Genetics and breast cancer. New York: Van Rostrand Reinhold, 1981.

${ }^{8}$ Kalache A, Vesey M. Risk factors for breast cancer. Clinics in Oncology $1982 ; 1: 661-78$.

${ }^{9}$ Anderson DE. Genetic study of breast cancer: identification of a high risk group. Cancer 1974;34:1090-7.

" Fraumeni JF Jr. Clinical patterns of familial cancer. In: Mulvihill JJ, Miller RW, Fraumeni JF Jr, eds. Genetics of human cancer. New York: Raven Press, 1977:223-56. (Progress in cancer research and therapy. Vol 3.)

11 Lynch HT, Krush AJ, Thomas RJ, Lynch J. Cancer family syndrome. In: Lynch HT, ed. Cancer genetics. Springfield, Ill: Charles C Thomas, 1976:355-88.

${ }^{12} \mathrm{Li}$ FP, Fraumeni JF. Soft-tissue sarcomas, breast cancer, and other neoplasms. A familial syndrome? Ann Intern Med 1969;71:747-52.

\section{The librarian's changing role}

The traditionally custodial role of the librarian is changing. The use of computers for cataloguing, information retrieval, and certain housekeeping procedures is commonplace, and the emphasis is increasingly on exploitation, not only of books and journals in the library but of information available elsewhere and in non-print form. A report by Matheson and Cooper, from the Association of American Medical Colleges, describes the library of the future in three stages: at 5-10 years, 10-20 years, and beyond 20 years. ${ }^{1}$ Ultimately they envisage an almost paperless library, relying on machinery to gather, retrieve, and transfer information. They foresee a time when research will be carried out by teams of researchers linked by computer irrespective of where they work individually.

Pessimistic librarians have nightmares that the technological age will cause redundancy, but the optimists will be encouraged by the American report. They will dream that they are the centre of the hospital's information system-teaching students how to formulate their own knowledge data bases, acting as information brokers for researchers and clinicians in assessing the results retrieved from numerous automated sources, and helping the administrators by contributing to the institute's data base on management information.

Those who make management and financial decisions must acknowledge that the technology exists to provide advanced systems for providing the right information to the right person at the right time. There is a danger that individuals, departments, or libraries will buy equipment for a specific project without considering whether a multipurpose machine, capable of linking with locally, nationally, and internationally available data bases, would be more efficient. There are networks for the dissemination of automated informationfor example, several libraries within the University of London have access to the records of each other's stocks. Health regions have similar links for the transfer of more general information, and there is software for minicomputers to access on line information retrieval data bases.

Computers can provide three particularly valuable services. Firstly, to remove dull routines-for example, automated systems which record and cancel loans, reserve material, send overdue notes, and order books. Secondly, to increase efficiency, such as using systems to transmit interlibrary loans. Thirdly, to extend the service of the "home" library by using data bases-not only Medline, Cancerline, Toxline, and so on but also statistical and management information.

Soon it will not matter that the library does not stock a certain journal: the text will be available on line and the library's or the individual's terminal will provide the relevant article immediately. It would be a pity, however, if libraries no longer provided printed journals and books, as browsing is important and many major discoveries in medicine must have been initiated or helped by serendipity.

Today's readers must find it hard to imagine a completely automated library, equipped with terminals and visual display units instead of books and journals, with workers at home or in their offices or laboratories tapping keys and reading from screens. The computer must be treated as a useful slave, not a master. Should we be aiming at a completely automated society, where information is king, where every home and office has access to the whole sum of knowledge? Can too much on line information be provided? Librarians 